\title{
Les collégiales de Bourgogne au Moyen Âge. Quelques résultats d'un programme de recherches
}

\section{Vincent Tabbagh}

\section{(2) OpenEdition}

1 Journals

\section{Édition électronique}

URL : https://journals.openedition.org/cem/6842

DOI : $10.4000 /$ cem.6842

ISSN : 1954-3093

Éditeur

Centre d'études médiévales Saint-Germain d'Auxerre

\section{Édition imprimée}

Date de publication : 15 août 2008

ISSN : 1623-5770

\section{Référence électronique}

Vincent Tabbagh, «Les collégiales de Bourgogne au Moyen Âge. Quelques résultats d'un programme de recherches ", Bulletin du centre d'études médiévales d'Auxerre | BUCEMA [En ligne], 12 | 2008, mis en ligne le 01 juillet 2008, consulté le 22 septembre 2022. URL : http://journals.openedition.org/cem/ 6842 ; DOl : https://doi.org/10.4000/cem.6842

Ce document a été généré automatiquement le 22 septembre 2022.

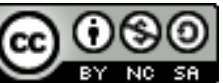

Creative Commons - Attribution - Pas d'Utilisation Commerciale - Partage dans les Mêmes Conditions 4.0 International - CC BY-NC-SA 4.0

https://creativecommons.org/licenses/by-nc-sa/4.0/ 


\title{
Les collégiales de Bourgogne au Moyen Âge. Quelques résultats d'un programme de recherches
}

\author{
Vincent Tabbagh
}

1 Près de dix ans après la présentation du projet de recherches sur les collégiales de Bourgogne au Moyen Âge ${ }^{1}$, au moment où elles acquièrent une réelle existence historiographique et entrent progressivement dans une base de données à l'échelle nationale ${ }^{2}$, il semble intéressant de mettre en évidence quelques acquis et de repérer les questions en suspens, d'autant plus qu'elles sont maintenant l'objet d'une définition réellement clarifiée mettant en avant leur sécularité, leur fonction liturgique par le chant en commun de l'office divin et l'autonomie qui les distingue nettement des collèges de chapelains dans les cathédrales comme des méparts et autres sociétés de prêtres ${ }^{3}$.

2 L'ampleur du phénomène n'est pas négligeable, puisque leur présence se repère à toutes les époques, dans une répartition spatiale bien équilibrées pour l'ensemble de la région. La Bourgogne parait solidement pourvue : alors que sept collégiales ont existé en moyenne dans chaque diocèse de France au Moyen Âge, celui de Chalon-sur-Saône, modeste, en a compté huit, Auxerre dix-sept, Autun vingt-deux et Langres vingt-sept. Une comparaison s'impose tant avec les établissements de chanoines réguliers qu'avec les couvents mendiants ; si la supériorité numérique des collégiales est évidente, reste à mesurer soigneusement la réalité des influences : quelle place la Chapelle-au-Duc et la Chapelle-aux-Riches tiennent-elles dans la vie religieuse des Dijonnais face à l'abbaye de chanoines augustins de Saint-Étienne et aux trois maisons de Frères?

3 À toutes les époques depuis la réforme d'Aix en 816 au moins, les collégiales ont relayé la présence de l'Église de la cité à l'intérieur du diocèse, d'abord par la relation d'autorité et même de possession qui les soumettaient à l'ordinaire et au presbyterium de la cathédrale ${ }^{4}$, non moins nettement aussi à la fin du XII ${ }^{\mathrm{e}}$ et au début du XIII ${ }^{\mathrm{e}}$ siècle lorsque la territorialisation de leur pouvoir conduit les évêques à créer des réseaux de collégiales dans les villes secondaires de leur diocèse qui s'en trouvaient encore 
dépourvues. En particulier, parce que leurs chanoines sont en même temps curés des paroisses avoisinantes dont elles détiennent souvent le patronage, elles font figure d'intermédiaires entre les autorités diocésaines et les paroisses, non sur le plan administratif aux mains des doyens ruraux, mais sur celui du rayonnement spirituel et culturel par la qualité d'un personnel bien formé et remarquablement stable, capable d'innovations pastorales et sensible aux accents nouveaux et aux attentes des fidèles ${ }^{5}$.

4 La souplesse de cette institution lui permet de rester le seul cadre de création d'églises privées importantes après la Réforme grégorienne. Elle joue donc un rôle essentiel dans les stratégies de fondation des grandes familles châtelaines et le développement des bourgs castraux. Une structure complexe unissant la grande forteresse de sommet, qui intègre la collégiale dans ses murailles ou dans son baile, et un prieuré de piémont ou de vallée à quelque distance, détenteur d'une fonction paroissiale plus ou moins développée, se répète dans plusieurs exemples bourguignons, à Vergy, Montréal, Thilen-Auxois, Donzy et Grancey ${ }^{6}$. La question mérite d'être creusée pour saisir les ressorts profonds d'un dispositif qui met en jeu aussi bien les relations des châtelains, exerçant leurs responsabilités spirituelles, avec les différents milieux ecclésiastiques, que l'organisation spatiale, plus ou moins figurative, des lieux de culte d'un territoire donné. Les $\mathrm{XII}^{\mathrm{e}}$ et $\mathrm{XIII}^{\mathrm{e}}$ siècles ont certainement vu un déclin des fondations de l'aristocratie laïque, au moment où les évêques prenaient au moins en partie le relais, mais la fin du Moyen Âge connait un incontestable renouveau du phénomène, aussi bien dans le cadre des châteaux que dans celui des villes, certains fondateurs obtenant même la collation des prébendes de leur collégiale sans aucune intervention d'une quelconque autorité ecclésiastique, Nicolas Rolin pour Notre-Dame-du-Chatel à Autun par exemple ${ }^{7}$.

5 Sa présence fréquente dans les bourgs castraux et les étapes de la création du réseau font de la collégiale un marqueur d'identité urbaine, car on n'en rencontre pas de proprement villageoise, sans lien avec un château, sauf dans le cas de Cervon au diocèse de Nevers, établissement très ancien né du culte d'un saint local. La collégiale périurbaine, héritage des anciennes basiliques, fréquente à l'époque carolingienne, semble s'effacer par le développement des communautés de chanoines réguliers qui les remplacent souvent au début du XII ${ }^{\mathrm{e}}$ siècle. Cependant, dans le bourg ou la ville, le chapitre de séculiers ouvre à des fidèles de fortune modeste, mais qui jouissent de la liberté juridique et donc de la capacité de transmission des patrimoines, le champ de la prière pour les morts et de la construction d'une mémoire familiale. La création, multipliée à partir du XIII siècle, d'anniversaires desservis par ces communautés sacerdotales plus ou moins nombreuses fait pénétrer un monde de laboureurs, modestes propriétaires terriens, artisans et petits marchands dans une promotion sociale et spirituelle jusque-là réservée à une aristocratie que ses générosités liaient au monde monastique ${ }^{8}$.

6 Un domaine parmi d'autres reste à défricher, encore timidement abordé : les multiples résonances économiques de la présence d'une collégiale, qui prélève des redevances, reçoit des fondations, améliore l'exploitation du sol, consomme quotidiennement de multiples produits, finance des constructions et des commandes artistiques, achète des rentes et prête de l'argent ${ }^{9}$.

7 L'étude de ce type d'établissement doit apporter encore beaucoup à l'histoire castrale, urbaine, économique et bien sûr ecclésiastique et spirituelle de la Bourgogne médiévale, d'autant plus que, parmi les établissements les plus influents, si Beaune 
commence à être mieux connu, il n'en va pas de même pour Avallon, Saulieu et tant d'autres.

\section{NOTES}

1. V. TABBAGH, « Un projet de recherches : les collégiales de Bourgogne au Moyen Âge », Annales de Bourgogne, 71 (1999), p. 99-118.

2. A. MASSONI, «Un nouvel instrument de travail pour la communauté scientifique : le répertoire des collégiales séculières de France à l'époque médiévale ", Revue d'histoire ecclésiastique, 102 (2007), p. 915-939.

3. G. TARBOCHEZ, Les méparts à Dijon (XIVe-milieu XVI e siècle). Étude d'une institution ecclésiastique médiévale particulière, mémoire de DEA d'histoire du droit, université de Bourgogne, 2001 ; EAD., « Nouveaux développements sur les méparts : les origines des communautés de prêtres à Dijon (XIV ${ }^{\mathrm{e}}-\mathrm{XV}^{\mathrm{e}}$ siècle) ", Mémoires de la Société pour l'histoire $d u$ droit et des Institutions dans les anciens pays bourguignons, comtois et romands, 59 (2002), p. 189-205.

4. V. TABBAGH, «Cathédrales et collégiales au Moyen Âge : rivalité et complémentarité », in M. FOURNIÉ (dir.), Les collégiales dans le Midi de la France au Moyen Âge, actes de l'atelierséminaire des 15 et 16 septembre 2000 (Carcassonne), Carcassonne, 2003, p. 277-287. 5. J-P. BRELAUD, «Les chanoines de la collégiale Notre-Dame de Beaune », Recueil des travaux du Centre beaunois d'études historiques, 17 (1999), p. 9-77. A. DESBROSSE, Liturgie, culte et vie religieuse autour de la collégiale Notre-Dame de Beaune du XIVe siècle à 1530, mémoire de maîtrise d'histoire, université de Bourgogne, 2002. v. TABBAGH, "Construction sacrée, réforme spirituelle et vénération des saints au milieu du $\mathrm{XV}^{\mathrm{e}}$ siècle : l'exemple de la collégiale de Vergy ", in Les clercs, les fidèles et les saints en Bourgogne médiévale, Dijon, 2005, p. 115-130.

6. V. TABBAGH, « Une entreprise de piété seigneuriale : la fondation de la collégiale de Grancey (1361) », Cahiers Haut-Marnais, 232-233 (2003), p. 69-84 ; ID., « Saint-Denis de Vergy, un exemple de collégiale castrale au Moyen Âge », La Quintefeuille, bulletin d'information de la Société d'histoire et d'archéologie du Pays de Vergy, 5 (2007), p. 16-23.

7. V. TABBAGH, «Les fondations de collégiales en Bourgogne aux XIVe et XV siècles », in M. FOURNIÉ (dir.), Les collégiales..., op. cit., p. 193-218.

8. V. TABBAGH, « Communauté canoniale et identité urbaine : l'exemple de la collégiale de Montréal (diocèse d'Autun) », in Le clergé et la ville au Moyen Âge, actes du colloque tenu à Besançon en 2005, à paraître.

9. J.-P. BRELAUD, « La mise en valeur du patrimoine viticole de quelques fondations beaunoises à la fin du Moyen Âge ", Cahiers d'Histoire de la vigne et du vin, 5 (2005), p. 31-48 [La vigne et les hommes en Bourgogne et alentour. Propriétés et propriétaires (XIV ${ }^{e}$ XXIe siècle), actes des premières rencontres " Aujourd'hui, l'histoire des Bourgognes ", Beaune, 2005] ; ID., « Les chanoines dans la campagne. Quelques remarques sur les prébendes du chapitre de Notre-Dame de Beaune », Bulletin trimestriel du Centre beaunois d'études historiques, 25 (2007), p. 5-20. 
INDEX

Mots-clés : collégiale

Index géographique : France/Bourgogne 